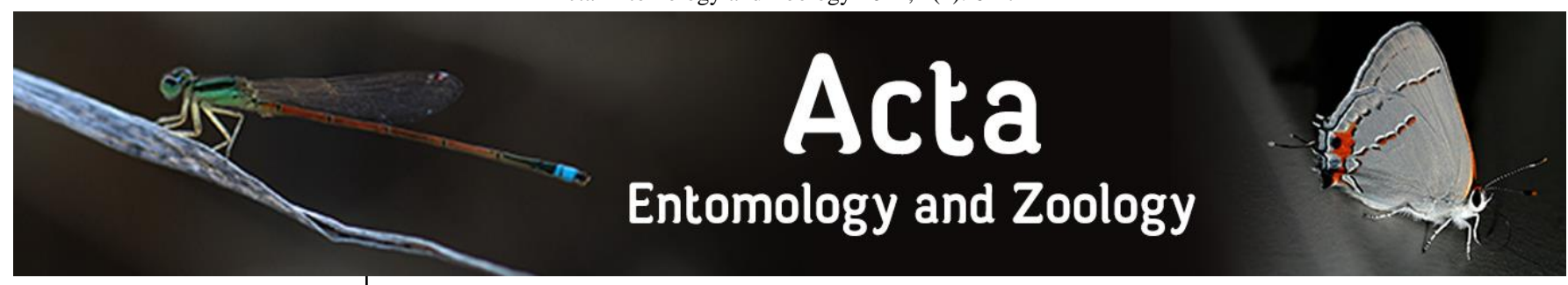

E-ISSN: 2708-0021 P-ISSN: 2708-0013 www.actajournal.com AEZ 2021; 2(1): 61-72 Received: 02-11-2020 Accepted: 28-12-2020

Hanan Salah El-Din Taha Central Agricultural Pesticide Laboratory, Dokki, Giza, Egypt
Corresponding Author: Hanan Salah El-Din Taha Central Agricultural Pesticide Laboratory, Dokki, Giza, Egypt

\section{Survivorship assessment for Spodoptera littoralis susceptible and field population after insecticide sublethal dose treatment}

\author{
Hanan Salah El-Din Taha
}

DOI: https://doi.org/10.33545/27080013.2021.v2.i1a.32

\begin{abstract}
Spodoptera littoralis (Lepidoptera noctuidae) (Boisd) is the most economic and series pest in Egypt with highly fecundity and dangerous attacking many crops. Insecticide efficiency trials showed failure and need more investigation periodically by many subject area. Susceptible laboratory reared population and field collected batches were subjected to bioassay of time mortality of the life survivors recording is the data producer by treating larvae with sublethal dose $\left(\mathrm{LC}_{30}\right)$ of insecticides candidates for this testing. Time-mortality data are improved method involves proportional survival and hazards modeling, known as Cox regression. The survival analysis of $S$. littoralis treated with sublethal dose of some insecticides exhibit slight differences in the median survival time (LT50) observed for each insecticide, where the higher values was 224.4 hour for metaflumezone and the smallest was 170.1 for pyridalyl in susceptible population while in field, the higher was 336 for indoxacarb and the smallest was 144 hour for imidacloprid. The median survival time was 265 for susceptible control and 375 hour for field control. Log rank test exhibit significant differences among treatments for susceptible (Logrank test, $Z=259.91$, d.f. $=4, p<0.001$ ) and field (Log-rank test, $Z=297.48$, df. $=4, p<0.001$ ). Hypothesis testing were computed for testing the survival curves, and every two hazard rates equality, at all times less than the maximum observed. Survival curves within insecticide groups and within population and control were differ according to p-values are less than 0.05 , verify the null hypothesis is success to be rejected. Some hazard rates decreases with time in both population. The hazard ratios of insecticides in relation to control was $95 \%$ confidence intervals of the susceptible and field calculated were smaller than one prove great indication that field population were dying at a significantly slower rate than susceptible, and males population of some insecticides have more chance to die at any point in time more than males from the susceptible. The results for field population were achieved only $1 \%$ of population survived at 555 hour, from 20 to $30 \%$ at 336 hour, from 30 to $40 \%$ and from 40 to $50 \%$ after treatment for all pesticide tested, where population stages were old moths, emerged moth, pupae and $5^{\text {th }}$ instar larvae respectively. This result evidenced that all insecticide tested at low concentrations treatment through a long period of exposure, must stimulate a continuous mortality and the time mortality assay using Kaplan-Meier and Cox regression analysis methodology were accurate and provide clear decision about pesticide toxicity, efficiency status and differences.
\end{abstract}

Keywords: Spodoptera littoralis, sublethal dose, economic

\section{Introduction}

The continually pest exposure to a variety of insecticides were associated with rapid development of insecticide resistance because of selection pressure intensity in agricultural eco-systems. IRM are more flexible deportment methods for insecticide operations, besides a new active ingredients introduction or increasing insecticide diversity in space and time. The long-lasting insecticide products considered a difficult tool in insecticide resistance management strategies options and application precisely in rotations and need more studies. The insecticide that proved to be insufficient control must be removed and switch to a different insecticide. The insecticide effect and strength on pest control assessment attains by different biological assays for measuring the direct the dose response relationship Sternberg and Thomas (2018) ${ }^{[28]}$. The need for analysing time to death data recently arises in a number of recommended pesticide used to control pests to compare the post treatment duration of the pest individual can still alive as effect of the lower insecticide dose efficiency to judge manipulation in charity. The Dose or concentration-mortality assay can determine the median lethal dose or concentration causes 50\% of insect deaths at time-mortality experiments at a single point of insect deaths event recording after treatment during short 
time with varying amount of insecticide. Additional ways, is the repeated mortality measurements that count a time requirements of experiment (once-time- dose- mortality) give the lethal time $\mathrm{LT}_{50}$ which the time to kill $50 \%$ of the given population. Throne et al., (1995) ${ }^{[29]}$, Preisler, and Robertson, (1992) take this kind of analysis as decisions about using logistic regression to analyse relationship between dose, mortality and between time to estimate $\mathrm{LD}_{50}$ and $\mathrm{LT}_{50}$ respectively. However, using cumulative mortality and the cumulative probability of survives according to administrating the predetermined definite dose of insecticide concentration treatment, after serial times of effects were more appropriate. Accurately until the end of the insect pest lifecycle, will give the median survival time from larvae treatment day until moths emerging and die to determine the sub lethal ti me (day) that kill 0.5 of the population. It can perform by using Aalen-Nelson Estimator) or the closely related Kaplan-Meier survival analysis estimates (Kaplan and Meier, 1958) ${ }^{[18]}$. This by assuming that: at any time pest individuals have the same survival predictions as others followed, the survival probabilities showing the mortality variation over time are the same for any insecticide and the event happens is the only varied at that time specified. Generally, it considered as specific methodology analysis for the detection of low-level insecticide resistance or insecticide poor efficiency Holbrook et al. $2002^{[8]}$. Survival time are data can measure the time to a certain event such as death, failure, response, separation or the development of a given disease Brevik, et al., (2018) ${ }^{[3]}$ and Etikan et al., (2017) ${ }^{[13]}$. Recently many papers stated that survival analysis is habitually uses in human public health studies to estimate how long a patient will survive fronting a disease and effects or compute the time to death following any hurt disease.

In this study, a Kaplan-Meier survival analysis accomplished to organize comparison between insecticides varied in their mode of action against two strains of Spodoptera littoralis (Boisd.) susceptible and field strain treated with candidate insecticide sublethal dose. To determine if insecticides by that dose can kill considerable number of a proper pest population attacking such crop, and how much number can pass to the next generation.

\section{Materials and Methods \\ Insects and insecticides}

Susceptible strain of cotton leaf worm Spodoptera littoralis (Boisd.) (Lepidoptera: noctuidae) used in this study mass reared in standard lab conditioned about many years in agriculture research center rearing laboratory rooms apart from insecticide exposure according to (Shaaban etal., 1985) [27]. Otherwise Kalubia governorate field strain larvae of cotton leaf worm collected from cotton plant and used directly in bioassays alongside with the susceptible by applicant insecticides.

Insecticides used were provided by central agricultural pesticide laboratory as formulated materials. The chemical name, trade name, active ingredient percentage and field rate of the formulated insecticides were as follows: organophosphate compounds were chlorpyrifos (Tannker $48 \%$ EC, cm/l), dimethoate (Ares 40\% EC, cm/l). Nicotinoid class was imidacloprid (Condorfast 35\% SC, $\mathrm{cm} / \mathrm{l}$ ). Pyrethroid was cypermethrin (Biomethrin10\% EC, $\mathrm{cm} / \mathrm{l})$. Insect Growth Regulator was hexaflumeron (Dimeuron 10\% EC, cm/l), lufenuron (Match 5\% EC, cm/l).
Metaflumezone (Technomizone $22 \% \mathrm{SC}, \mathrm{cm} / \mathrm{l}$ ), novaluron (Roxy 10\% EC, cm/l). Unclassified group of insecticide was pyridalyl (Peleo 50\% EC, $\mathrm{cm} / \mathrm{l}$ ) and carbamate was Indoxacarb (Pret 15\% EC, cm/l).

\section{Concentration-mortality bioassays}

Bioassays performed on all strains using a leaf dip method according to Paramasivam and Selvi (2017) [26] as proceeding. Uninfected cotton Leaves individually and efficiently dipped in subsequent diluted solutions of five insecticide concentration, and left to dry and controls dipped in water only. Afterward, treated leaves placed individually in 9-diameter petri dish filled with 10 individual of 1-dayold, $4^{\text {th }}$ instars larvae and 3 replicate done for each concentration. The dishes preserved in controlled conditions at $25 \pm 2{ }^{\circ} \mathrm{C}$ and 16:8 $\mathrm{h}$ light: dark. Mortality was recorded $24 \mathrm{~h}$ or $48 \mathrm{~h}$ after treatment according the insecticide. Recorded leaf-dip bioassay data submitted to Polo Computer Software program for $\mathrm{LC}_{30}, 50,90$, estimation according to Finney (1971) ${ }^{[14]}$, including correction of mortality.

\section{Sublethal dose treatment}

Sublethal effect of the insecticides on S.littoralis survivorship were performed by dipping cotton leaves in each insecticide solution containing the $\mathrm{LC}_{30}$ concentration, which previously determined for each insecticide by the baseline assay. After drying of the plant, leaves introduced to feed about 300 fourth instars larvae for each insecticide in one big container for 24 or 48 hour after that survived larvae collected and placed in new container and fed on fresh untreated leaves. Survived larvae recorded daily at constant time intervals until moth emergences, ovipositon and die, then considered the end of the counts.

\section{Survivorship assessment procedure}

The mean idea of this test according to Goel et al., $2010^{[15]}$ and Clark et al., $2003^{[6]}$ is calculating the survival function (time) which is the probability that an individual will survive or die after a given time. The survival probability and the successive probabilities from one intervals to the next that can multiplying together to give cumulative survival probability, then the estimated probability refers to changes in value of each event in its group. The survival probability at each interval is calculated as the number of survivors divided by the number of individuals at risk by this formula: $S_{t}=$ no. of individuals living at the start (n)no. of individuals died(d) / no. of individuals living at the start. This step must followed by the measurement of median survival time $\left(\mathrm{LT}_{50}\right)$ according to Brookmeyer and Crowley (1982) [4] that means, the total probability of survival at the end of a time is 0.50. Alternatively, plotted directly from the survival plot lines. Survival function, according to Lee and Wang (2003) ${ }^{[20]}$, is the probability that an individual will survive longer than a specified time $t$. The output of this analysis were included: firstly, the hazard ratio of the risk means the risk ratio that occurring at any time between groups. The ratio between $\mathrm{s}(\mathrm{t})$ and $\mathrm{h}(\mathrm{t})$ which is calculated by this formula $\mathrm{h}(\mathrm{t})=-\mathrm{d} / \mathrm{dt}(\operatorname{logs}(\mathrm{t}))$, and the cumulative hazard is $\mathrm{Ht}=-\mathrm{In}(\mathrm{St})$. The second output result were the log-rank test: is a statistical method to compare survival function and to test statistically difference effect of the survival times between two groups to death variable. Its calculation method as follows: 


$$
x^{2}(\log \text { rank })=\frac{\left(O_{1}-E_{1}\right)^{2}}{E_{1}}+\frac{\left(O_{2}-E_{2}\right)^{2}}{E_{2}}
$$

Where the $\mathrm{O}_{1}$ and $\mathrm{O}_{2}$ are the total no. of observed events between two group respectively, and $E_{1}$ and $E_{2}$ is the total no. of expected events. The expected no. of events calculated as the death risk at that time multiplied by the no. alive in the group. Under the null hypothesis, the death risk $=$ (no. of deaths/no. alive). Finally the Cox proportion hazard test: is to test the probability of dying at given time as result of other independent variables effect, (Mantel and Haenszel, 1959; Cox, 1972) [21, 7] and test Confidence intervals calculated to prove that there is no significant difference between two groups. If test statistic value is less than the critical value (using chi square table) for degree of freedom.'

\section{Statistical analysis}

The data for serial time-death recording after predetermined sub lethal dose treatment $\left(\mathrm{LC}_{30} \mathrm{ppm}\right)$ submitted to survival analysis statistic procedures estimator over the KaplanMeier (1958) ${ }^{[18]}$ analysis time to event data for comparing group insecticides with control. All the analysis steps output was the non-parametric procedure (Survival or failure (the death event) probabilities and its confidence intervals, Logrank test method, Hazard ratios and Cox regressions) at a definite times, and in addition to survival reliability curves, hazard rate and hazard ratio chart were performed using NCSS2020 Computer Software (v.2019). The variable censor was coded zero if the event occurred at the exact time of the event occurrence. The control was omitted in the data set because there was no mortality for larva exposed to water only.

\section{Results and Discussions \\ Dose-mortality assay}

The results of the S.littoralis susceptible population treated with insecticide tested and calculation was completed using the probit of Dose-mortality assays according to Finney probit analysis, that frequently used to detect the shift of response at one time of death recording are found in (Table 1). Generaly $\mathrm{LC}_{50}$ values in ppm showed slight variations between insecticide classes and group and there was no death in control, which treated of water. In addition, kalubia field, is a different set of this pest population, result of $\mathrm{LC}_{50}$ and $\mathrm{LC}_{90}$ values, are found in (table 2).Toxicity lines fit showed low $\chi^{2}$ values ranged from $(0.16$ to 4.3$)$ and high $\mathrm{p}$ values ranged from (0.11 to 0.96), proving accuracy to estimate the mortality curves for susceptible population. Indoxacarb had the highest toxicity followed by hexaflumeron, lufenuron, chlorpyrifos, pyridalyl, deltamethrin, novaluron, metaflumezone and imidacloprid with relative toxicity of 32.20, 739.43 and $1074.07 \mathrm{ppm}$, in susceptible population, respectively (Table 1). However, $\mathrm{LC}_{50} \mathrm{~s}$ of the field were the highest values was329 ppm for imidacloprid and $58.2 \mathrm{ppm}$ for dimethoate and the lowest was $3.7 \mathrm{ppm}$ for hexaflumuron. Some insecticide had $\mathrm{LC}_{90}$ were lower than the field label rate and considered more effective. Statistical analysis of $\mathrm{LC}_{50} \mathrm{~s}$ significance proved no significant differences between insecticide each other and time but between susceptible population and time $(\mathrm{F}=$ $1.76, \mathrm{df}=2, \mathrm{p}=0.193$ ) and field between population and time $(\mathrm{F}=2.3, \mathrm{df}=2, \mathrm{p}=0.055)$. There are no significant differences between $\mathrm{LC}_{50}$ of field and susceptible strain.

Table 1: Probit analysis of $S$. littoralis susceptible population insecticide toxicity.

\begin{tabular}{|c|c|c|c|c|c|c|c|}
\hline Insecticide & Slope \pm SE & LC $\left._{\mathbf{3 0}} \mathbf{( 9 5 \%} \mathbf{C I}\right)$ & $\left.\mathbf{L C}_{\mathbf{5 0}} \mathbf{( 9 5 \%} \mathbf{C I}\right)$ & LC $\left._{\mathbf{9 0}} \mathbf{( 9 5 \%} \mathbf{C I}\right)$ & $\boldsymbol{\chi}^{\mathbf{2}}$ & pvalue & RT \\
\hline Chlorpyrifos & $1.76 \pm 0.17$ & $13.86(10.4-17.19)$ & $27.48(22.84-32.4)$ & $146.3(111.3-214.3)$ & 4.03 & 0.25 & 3.123 \\
\hline Dimethoate & $1.58 \pm 0.20$ & $29.1(21.3-36.3)$ & $62.34(51.6-76.1)$ & $400.7(262.2-794.3)$ & 4.06 & 0.13 & 7.084 \\
\hline Imidacloprid & $1.29 \pm 0.16$ & $42.7(32.9-51.1)$ & $108(92.4-132.7)$ & $1051(609-2596.4)$ & 1.78 & 0.409 & 12.273 \\
\hline Cypermethrin & $1.8 \pm 0.11$ & $3.3(2.0-5.4)$ & $6.45(3.96-10.5)$ & $32.9(20.2-53.6)$ & 0.33 & 0.18 & 1.46 \\
\hline Hexafleumeron & $1.86 \pm 0.21$ & $4.6(3.27-5.88)$ & $8.86(7.1-10.5)$ & $43.1(32.7-64.98)$ & 4.3 & 0.11 & 1.007 \\
\hline Lufenuron & $2.2 \pm 0.21$ & $8.9(6.7-10.9)$ & $15.4(12.7-17.9)$ & $58.5(48.3-75.9)$ & 3.9 & 0.14 & 1.750 \\
\hline Metaflumezone & $1.78 \pm 0.15$ & $31.3(25.7-36.9)$ & $61.6(52.6-73.1)$ & $322.6(235.4-497.7)$ & 0.27 & 0.96 & 7.000 \\
\hline Novaluron & $2.5 \pm 0.23$ & $30.0(25.0-34.8)$ & $48.2(42.2-54.8)$ & $153.4(125.4-201.4)$ & 3.5 & 0.16 & 5.477 \\
\hline Pyridalyl & $1.68 \pm 0.17$ & $21.3(16.5-26.0)$ & $43.6(36.2-52.9)$ & $251.6(177.1-415.9)$ & 4.0 & 0.14 & 4.955 \\
\hline Indoxacarb & $1.89 \pm 0.22$ & $6.7(4.7-8.5)$ & $12.6(10.2-15.0)$ & $59.9(66.6-154.4)$ & 0.16 & 0.92 & 1.432 \\
\hline
\end{tabular}

$\mathrm{SE}=$ standard error of the slope from the logisticmethod. $\mathrm{CI}=$ confident intervals. Resistance ratios. $\mathrm{RT}=$ relative toxicity means the division of each LC 50 by the less value of the susceptible population.

However, in field population p-values of the probit analysis were ranged from 0.027 to 0.78 for and $\chi 2$ ranged from 1.07 to 6.1. The resistance ratios were represent dissimilar values (ranged from 0.448 to 1.429 ) and differed from each other (Table 2). The highest RR were 7 for imidacloprid then 1.429 was for indoxacarb and the lowest was 0.42 for pyridalyl. When comparing $\mathrm{LC}_{50}$ values with field rate some insecticide $\mathrm{LC}_{50}$ like indoxacarb, lufenuron and chlorpyrifos slightly are not enough to kill $50 \%$ of field population (Table 2). Nevertheless, other insecticide were below the field rate recommended concentration (insecticide lable), means this strain were very susceptible to those insecticide that considered newest chemical products used to control crop pests.

Table 2: Probit analysis of $S$. littoralis field population larvae insecticide toxicity.

\begin{tabular}{|c|c|c|c|c|c|c|c|}
\hline Insecticide & Slope \pm SE & $\mathbf{L C}_{\mathbf{3 0}} \mathbf{( 9 5 \%}$ CI) & LC $_{\mathbf{5 0}}$ (95\% CI) & LC $_{\mathbf{9 0}}$ (95\% CI) & $\boldsymbol{\chi} \mathbf{2}$ & Pvalue & RR \\
\hline Chlorpyrifos & $1.14 \pm 0.15$ & $11.3(5.4-17.9)$ & $32.7(21.5-43.6)$ & $433.0(287.9-827.1)$ & 1.07 & 0.78 & 1.190 \\
\hline Dimethoate & $1.86 \pm 0.16$ & $30.4(24.0-36.74)$ & $58.2(49.3-67.8)$ & $283.6(221.3-395.1)$ & 3.4 & 0.33 & 0.934 \\
\hline Imidacloprid & $2.5 \pm 0.347$ & $177.6(125.2-226.7)$ & $329.9(262.4-411.9)$ & $1069.9(783.8-1748.6)$ & 1.22 & 0.74 & 7.0 \\
\hline Cypermethrin & $1.94 \pm 0.11$ & $13.9(8.0-21.2)$ & $25.1(15.4-40.8)$ & $124.0(76.2-201.1)$ & 0.45 & 0.71 & 1.54 \\
\hline
\end{tabular}




\begin{tabular}{|c|c|c|c|c|c|c|c|}
\hline Hexafleumeron & $0.98 \pm 0.16$ & $1.16(0.31-2.3)$ & $3.97(1.888-6.0)$ & $80.1(48.7-200.4)$ & 3.53 & 0.31 & 0.448 \\
\hline Lufenuron & $2.55 \pm 0.25$ & $9.59(7.5-11.48)$ & $15.4(13.0-17.6)$ & $48.8(40.7-62.7)$ & 4.5 & 0.104 & 1.000 \\
\hline Metaflumezone & $1.57 \pm 0.187$ & $18.9(12.2-20.8)$ & $33.8(25.6-41.7)$ & $221.0(164.1-344.8)$ & 1.7 & 0.89 & 0.549 \\
\hline Novaluron & $1.8 \pm 0.24$ & $13.13(7.9-18.0)$ & $25.6(18.8-31.7)$ & $131.75(100.9-200.4)$ & 4.0 & 0.135 & 0.531 \\
\hline Pyridalyl & $0.95 \pm 0.10$ & $5.14(2.47-8.5)$ & $18.3(11.7-25.5)$ & $404.6(269.5-718.6)$ & 2.86 & 0.412 & 0.420 \\
\hline Indoxacarb & $2.6 \pm 0.20$ & $11.37(6.4-15.0)$ & $18.0(11.8-25.4)$ & $55.45(42.9-112.1)$ & 6.1 & 0.027 & 1.429 \\
\hline
\end{tabular}

$\mathrm{SE}=$ standard error of the slope from the logistic method. $\mathrm{CI}=$ confident intervals. Resistance ratios $(\mathrm{RR})=$

$\mathrm{LC}_{50}$ s and $\mathrm{LC}_{95}$ s of the four field strains, divided by the $\mathrm{LC}_{50}$ and $\mathrm{LC}_{95}$ of the lab strain

\section{Time mortality assay}

The survival and failure probabilities and the proportional hazards (Cox) modelling to analyze time-to-event data were calculated to obtain different result about determinig the percentage of mortality through series of time intervals records of larvae death and the rate of death alongside the pest lifecycle this results were in Table (3 and 4). This test including the cumulative survival probabilities, cumulative hazard function, and hazard rates, all of those represent the survival analysis machineries and the life table that constructed from a set of grouped of mortality failure and censor data. In addition to the hazard, ratios that used to compare directly the death rate of one group to that of a control group, similar to resistance ratios that used to assess insecticide resistance in the field populations that exhibit heterogeneity and such resistance phenotypes, these results were in (Table 5, 6, 7 and 8).

Table 3: Estimated Survival and its confidence Limits report for some insecticide sublethal toxicity against S.littoralis susceptible and field population.

\begin{tabular}{|c|c|c|c|c|c|c|}
\hline & \multicolumn{3}{|c|}{ Suseptible population } & \multicolumn{3}{c|}{ Field population } \\
\hline Insecticide & Larvae & Pupae & Moth & Larvae & Pupae & Moth \\
\hline Chlorpyrifos & $0.43(0.40-0.46)$ & $0.24(0.22-0.27)$ & $0.026(0.016-0.035)$ & $0.27(0.24-0.30)$ & $0.135(0.11-0.16)$ & $0.13(0.005-0.002)$ \\
\hline Dimethoate. & $0.44(0.41-0.47)$ & $0.23(0.21-0.26)$ & $0.02(0.013-0.03)$ & $0.27(0.24-0.31)$ & $0.14(0.11-0.16)$ & $0.014(0.005-0.02)$ \\
\hline Imidacloprid & $0.469(0.44-0.5)$ & $0.27(0.24-0.29)$ & $0.03(0.02-0.039)$ & $0.25(0.22-0.28)$ & $0.13(0.10-0.153)$ & $0.015(0.002-0.018)$ \\
\hline Cypermethrin & $0.43(0.39-0.46)$ & $0.24(0.21-0.27)$ & $0.025(0.016-0.036)$ & $0.36(0.33-0.4)$ & $0.2(0.17-0.22)$ & $0.016(0.008-0.025)$ \\
\hline Hexaflumero & $0.46(0.43-0.49)$ & $0.24(0.22-0.26)$ & $0.018(0.011-0.027)$ & $0.34(0.31-0.38)$ & $0.19(0.16-0.21)$ & $0.019(0.0097-0.0029)$ \\
\hline Metaflumezone & $0.51(0.49-0.54)$ & $0.31(0.28-0.34)$ & $0.033(0.023-0.043)$ & $0.35(0.31-0.38)$ & $0.16(0.13-0.18)$ & $0.012(0.004-0.02)$ \\
\hline Lufenuron & $0.47(0.44-0.56)$ & $0.25(0.22-0.28)$ & $0.019(0.012-0.028)$ & $0.33(0.3-0.37)$ & $0.18(0.15-0.2)$ & $0.02(0.008-0.03)$ \\
\hline Indoxacarb & $0.47(0.44-0.5)$ & $0.26(0.24-0.29)$ & $0.025(0.016-0.035)$ & $0.36(0.33-0.4)$ & $0.17(0.15-0.2)$ & $0.017(0.008-0.025)$ \\
\hline Thiametham & $0.47(0.44-0.496)$ & $0.28(0.25-0.304)$ & $0.03(0.021-0.041)$ & $0.33(0.3-0.36)$ & $0.17(0.16-0.2)$ & $0.019(0.009-0.027)$ \\
\hline Pyridalyl & $0.39(0.354-0.42)$ & $0.17(0.14-0.193)$ & $0.014(0.006-0.02)$ & $0.32(0.28-0.36)$ & $0.17(0.14-0.2)$ & $0.017(0.007-0.27)$ \\
\hline Control & $0.61(0.59-0.63)$ & $0.39(0.37-0.41)$ & $0.04(0.04-0.052)$ & $0.6(0.58-0.62)$ & $0.39(0.36-0.4)$ & $0.04(0.034-0.05)$ \\
\hline
\end{tabular}

Censored is the missing individual and failure is the individual failed to die and survived to the next time intervals.

The overall dead or individual didn't survive $\mathrm{LC}_{30}$ treatment after experiment finished was 74,72,70,68,78,74,76,56,73 and $72 \%$ and $90,90,93,85,87,85,86,80,85$, and $88 \%$ in susceptible and field population respectively, for chlorpyrifos, dimethoate, imidacloprid, thiamethoxam, lufenuron, hexaflumeron, cypermethrin, metaflumezone, indoxacrb, and pyridalyl respectively, as shown in commulative individual number at risk inside analysis. The mortality rate and the Kaplan-Meier survival curves of S.littoralis larvae treated with the different insecticide classes were not significantly different $(\mathrm{P}=0.00)$ from the control. The analysis of mortality rates also revealed that the effects of insecticide treatments within insect stages were $(\mathrm{F}$ $=1.189, \mathrm{df}=3, \mathrm{P}=0.306)$ in the susceptible population, but in the field population $(\mathrm{F}=0.642$, df $=2, \mathrm{P}=0.427)$ and the interaction between pest stages (Larvae-Pupae and Moth) were highly significant for the $(\mathrm{F}=1.189, \mathrm{df}=3, \mathrm{P}=0.306)$.
Generally, Survival was significant and affected by insecticide dose. The order and death rate in the two population was not always the same trend (Fig. 1, 2). Compare the daily commutative survival pattern for insecticide treatment groups had different probability of surviving with a control, while another took longer time to deaths. The survival analysis showed that the order and patterns of the lines of cumulative survival for the various insecticides were significant in both assays, Kurtosis Normality was -0.363 for susceptible but for field was 0.813 and p-values for susceptible was 0.716 and for field was 0.415 . Susceptible population showed survival curve lines were very closer or overlying also showed statistically no significant differences and no clear pattern $(p=0.0)$ in the rates (Skewness Normality 4.59). On the dissimilarity, field population showed divergent survival line (Skewness Normality 5.578) (Table 7). The dynamics of survival, observed increase of mortality caused an increase of the death rate because of serious damage to treated larvae through experiment duration (Fig 3, 4).

Table 4: Estimated Hazard and its confidence Limits report for some insecticide sublethal toxicity against S.littoralis susceptible and field population.

\begin{tabular}{|c|c|c|c|c|c|c|}
\hline & \multicolumn{2}{|c|}{ Susceptible population } & \multicolumn{3}{c|}{ Field pop[ulation } \\
\hline insecticide & Larvae & Pupae & Moth & Larvae & Pupae & Moth \\
\hline Chlorpyrifos & $0.84(0.77-0.92)$ & $1.41(1.30-1.52)$ & $3.68(3.33-4.10)$ & $0.006(0.0054-0.0069)$ & $0.004(0.003-0.005)$ & $0.0001(0.00150 .0017$ \\
\hline Dimethoate & $0.82(0.75-0.89)$ & $1.32(1.22-1.42)$ & $3.89(3.51-4.35)$ & $0.0057(0.005-0.0065)$ & $0.003(0.0024-0.0039)$ & $0.0014(0.0012-0.0016)$ \\
\hline Imidacloprid & $0.76(0.7-0.82)$ & $1.3(1.22-1.41)$ & $3.55(3.24-3.92)$ & $0.0051(0.0044-0.0059)$ & $0.0016(0.001-0.0023)$ & $0.0012(0.01-0.0014)$ \\
\hline Cypermethrin & $0.85(0.78-0.93)$ & $1.42(1.32-1.54)$ & $3.70(3.35-4.15)$ & $0.0035(0.0031-0.0041)$ & $0.001(0.0008-0.0016)$ & $0.0015(0.0013-0.0017)$ \\
\hline Hexaflumeron & $0.78(0.72-0.85)$ & $1.431 .33-1.54)$ & $4.0(3.61-4.492)$ & $0.0047(0.0003-0.0041)$ & $0.0004(0.003-0.0045)$ & $0.0015(0.0013-0.0017)$ \\
\hline
\end{tabular}




\begin{tabular}{|c|c|c|c|c|c|c|}
\hline Metaflumezon & $0.67(0.62-0.73)$ & $1.18(1.1-1.26)$ & $3.42(3.13-3.75)$ & $0.0035(0.003-0.004)$ & $0.0032(0.0025-0.004)$ & $0.0014(0.0012-0.0016)$ \\
\hline Lufenuron & $0.76(0.69-0.82)$ & $1.4(1.32-1.54)$ & $3.95(3.57-4.4)$ & $0.0043(0.0037-0.005)$ & $0.0028(0.0022-0.0035)$ & $0.0014(0.0012-0.0016)$ \\
\hline Indoxacarb & $0.76(0.69-0.82)$ & $1.34(1.24-1.44)$ & $3.7(3.36-4.12)$ & $0.002(0.0017-0.0024)$ & $0.0035(0.0029-0.0043)$ & $0.001(0.0001-0.0013)$ \\
\hline Thiametham & $0.77(0.70-0.83)$ & $1.29(1.19-1.39)$ & $3.51(3.19-3.89)$ & $0.0052(0.0046-0.0058)$ & $0.004(0.003-0.0048)$ & $0.0013(0.0012-0.0015)$ \\
\hline Pyridalyl & $0.95(0.87-1.04)$ & $1.79(1.65-1.9)$ & $4.47(3.93-5.21)$ & $0.0043(0.0037-0.005)$ & $0.0039(0.0032-0.0047)$ & $0.0012(0.0012-0.0013)$ \\
\hline Control & $0.5(0.47-0.54)$ & $0.95(0.89-0.99)$ & $3.14(2.96-3.35)$ & $0.0001(0.0001-0.005)$ & $0.0042(0.0034-0.0051)$ & $0.0002(0.0001-0.0001)$ \\
\hline
\end{tabular}

Censored is the missing individual and failure is the individual failed to die and survived to the next time intervals.

Some hazard rates decreases with time, others have a hazard rate that increases with time, some are constant, and some exhibit all three behaviors at different points in time. In fact, the subjects who die (fail) as well as subjects who are censored or not presented, the program survival datasets and computation required the start and the end of survival times and observations of censored or failed to perform several logrank tests and provides both the non-parametric and randomization test significance levels. The dataset contained 24-observation time (number of events) for each insecticide groups passing from the larvae, pupae, and moths that censored or failed. The results for field population were achieved only $1 \%$ of population survived at 555 hour, from 20 to $30 \%$ at 336 hour, from 30 to $40 \%$ and from 40 to 50 $\%$ after treatment for all pesticide tested, where population stages were old moths, emerged moth, pupae and $5^{\text {th }}$ instar larvae respectively. With observation of recording individuals escaping or dying accidentally, the delayed toxicity of insecticide tested may be reason of the differential sensitivity of $S$. littorlais according to age distribution and the accumulation of the insecticide compounds in bodies' leads to sensitivity variation. This result evidenced that all insecticide tested at low concentrations treatment through a long period of exposure, must stimulate a continuous mortality.
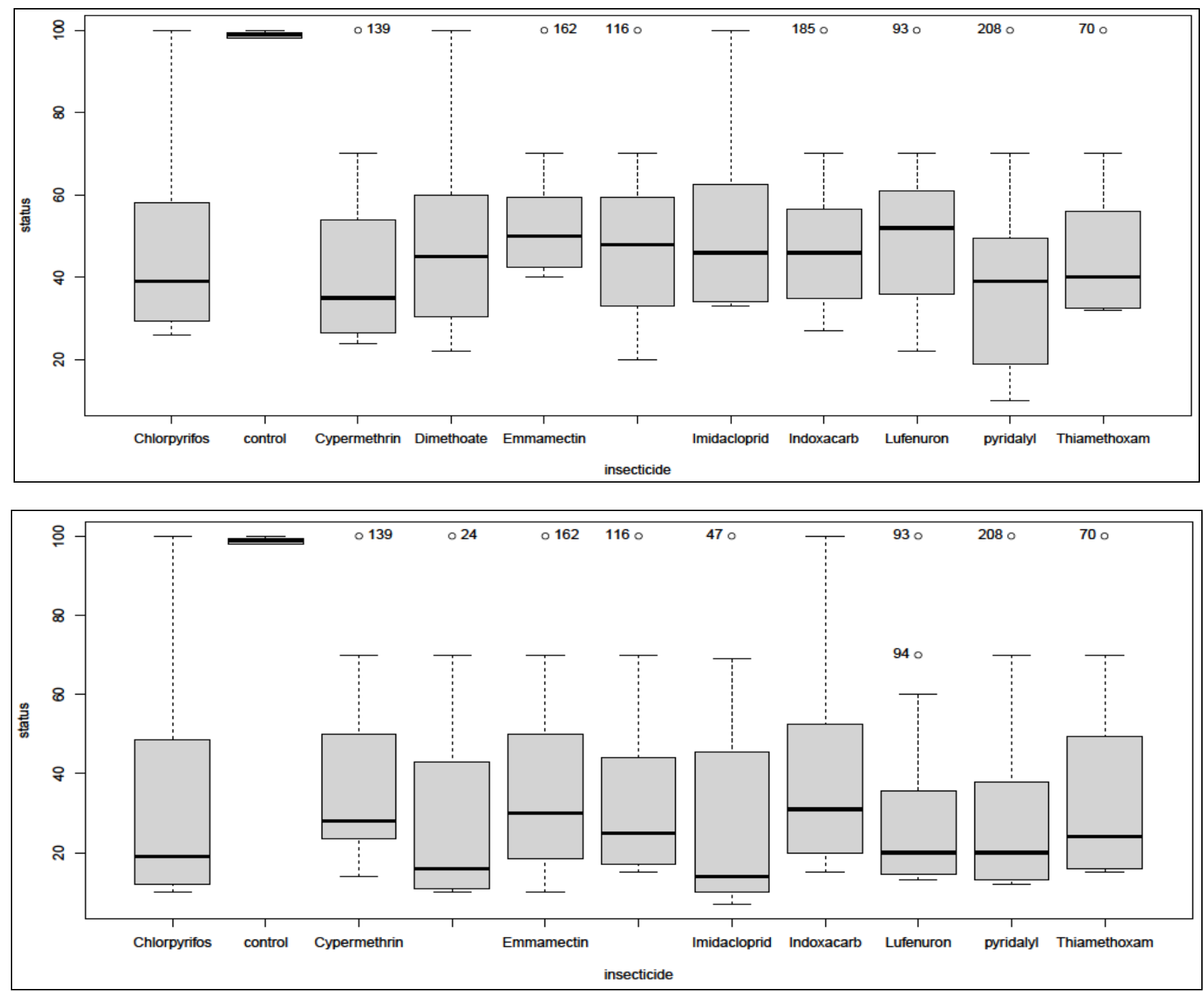

Fig 1: Susceptible and field population of $S$. littorallis status of surviving insecticide treatment, box plot differentiation between insecticides and population through comparing the center and spread of groups. The spread look differences and fill weight of ten insecticide treatment boxes. Median weight of groups not similar and the general weight of them more variable than other. Also there is differences between the centers of the group. The number above were Identifying the cause of outlier. Skewed data, the majority of data located in high side of the graph. Skewness indicated that data may be not normally distributed and refer to failure time, and some data Fail to die closely and more fail later. 
A slight differences in the median survival time $\left(\mathrm{LT}_{50}\right)$ observed for each insecticide, where the higher values was 224.4 hour for metaflumezone and the smallest was 170.1 for pyridalyl in susceptible population while in field, the higher was 336 for indoxacarb and the smallest was 144 for imidacloprid. The median survival time was 265 for susceptible control and 365.9 hour for field control (Table $5)$. The survival analysis of $S$. littoralis treated with sublethal dose of some insecticides indicated (Table 3, 4) exhibit significant differences among treatments for susceptible (Log-rank test, $Z=259.91$, d.f. $=4, p<0.001$ ) and field (Log-rank test, $Z=297.48, \mathrm{df} .=4, \mathrm{p}<0.001$ ) (Table 6). The survival of larvae was $100 \%$ in the control (without insecticide exposure) after $500 \mathrm{~h}$ of exposure. This result were similar to De Castro et al., $2013^{[9]}$, calculate high median survival time $\left(\mathrm{LT}_{50}\right)$ of predatory stinkbugs Podisus nigrispinus (hemipteran: pentatomidae) exposed chlorantraniliprole, methamidophos, spinosad, deltamethrin. However, when exposed to dried insecticide residues indicated significant differences among treatments.

Table 5: Median survival time and Restricted Mean Survival Time of the two population from Nonparametric Kaplan-Meier test.

\begin{tabular}{|c|c|c|c|c|c|c|c|c|}
\hline & \multicolumn{4}{|c|}{ Susceptible population } & \multicolumn{4}{|c|}{ Field population } \\
\hline Insecticides & Median (CL95\%) & RMST $(\tau)($ CL95\%) & \pm SE & MXL. & Median (CL95\%) & $\operatorname{RMST}(\tau)$ & $\pm \mathrm{SE}$ & MXL. \\
\hline Chlorpyrifos & $193.983(192-216)$ & $251.4(241.3-261.6)$ & 5.159 & 191.87 & $168(144-144)$ & $207.9(195.9-220)$ & 6.14 & 164 \\
\hline Cypermethrin & $191.158(192-216)$ & $251.7(241.1-262.3)$ & 5.390 & 189.18 & 192(168-192) & $258.5(245.3-271.8)$ & 6.75 & 254 \\
\hline Dimethoate & $195.325(216-216)$ & $245.1(236.0-254.2)$ & 4.639 & 192.33 & $168(144-144)$ & $214.4(201.3-227.5)$ & 6.67 & 163 \\
\hline Metaflumezone & $224.407(240-240)$ & $280.2(270.6-289.7)$ & 4.890 & 218.28 & $240(216-216)$ & $271.7(257.9-285.6)$ & 7.07 & 237 \\
\hline Hexaflumeron & $200.702(216-216)$ & $248.6(239.8-257.4)$ & 4.496 & 196.48 & $192(168-168)$ & $235.4(222.6-248.2)$ & 6.54 & 190 \\
\hline Imidacloprid & $208.825(240-240)$ & 279.1(269.0-289.1) & 5.152 & 204.89 & 144(144-144) & $219.8(205.1-234.5)$ & 7.48 & 141 \\
\hline Indoxacarb & $204.912(216-216)$ & $266.5(256.5-276.4)$ & 5.064 & 200.74 & $336(288-288)$ & $313.3(298.5-328.1)$ & 7.56 & 335 \\
\hline Lufenuron & $204.924(216-216)$ & & 4.393 & & & $230.8(216.6-245)$ & 7.23 & 163 \\
\hline Thiamethoxam & $206.313(216-216)$ & $266.6(256.2-277.0)$ & 5.316 & 202.49 & $168(168-168)$ & $228.2(216.2-240.2)$ & 6.12 & 163 \\
\hline Pyridalyl & $170.107(192-192)$ & $222.2(212.7-231.6)$ & 4.831 & 168.35 & $168(144-168)$ & $230.2(216-244.4)$ & 7.24 & 162 \\
\hline Control & 265.946 & $508.7(503-514.3)$ & 2.890 & 257.88 & 356.9 & $508.7(503-514.3)$ & 2.89 & \\
\hline
\end{tabular}

Median Estimates are based on an interval upper limit of $\tau=552.0$, the maximum observed time among all groups.

$M X L=$ Nonparametric test or Maximumlikelihood estimated for mean and median survival time.

$\operatorname{RMST}(\mathrm{t})=$ Restricted Mean Survival Time. $\pm \mathrm{SE}=$ Standard error of the mean.

The logrank test is testing the equality of hazard functions or estimated survival times. This test uses $\mathrm{W}(\mathrm{T})=$ one, that is, equal weighting, optimum power when the hazard rates of the $\mathrm{K}$ populations are proportional to each other which is only valid for equal censoring (Lee and Wang (2003) ${ }^{[20]}$.

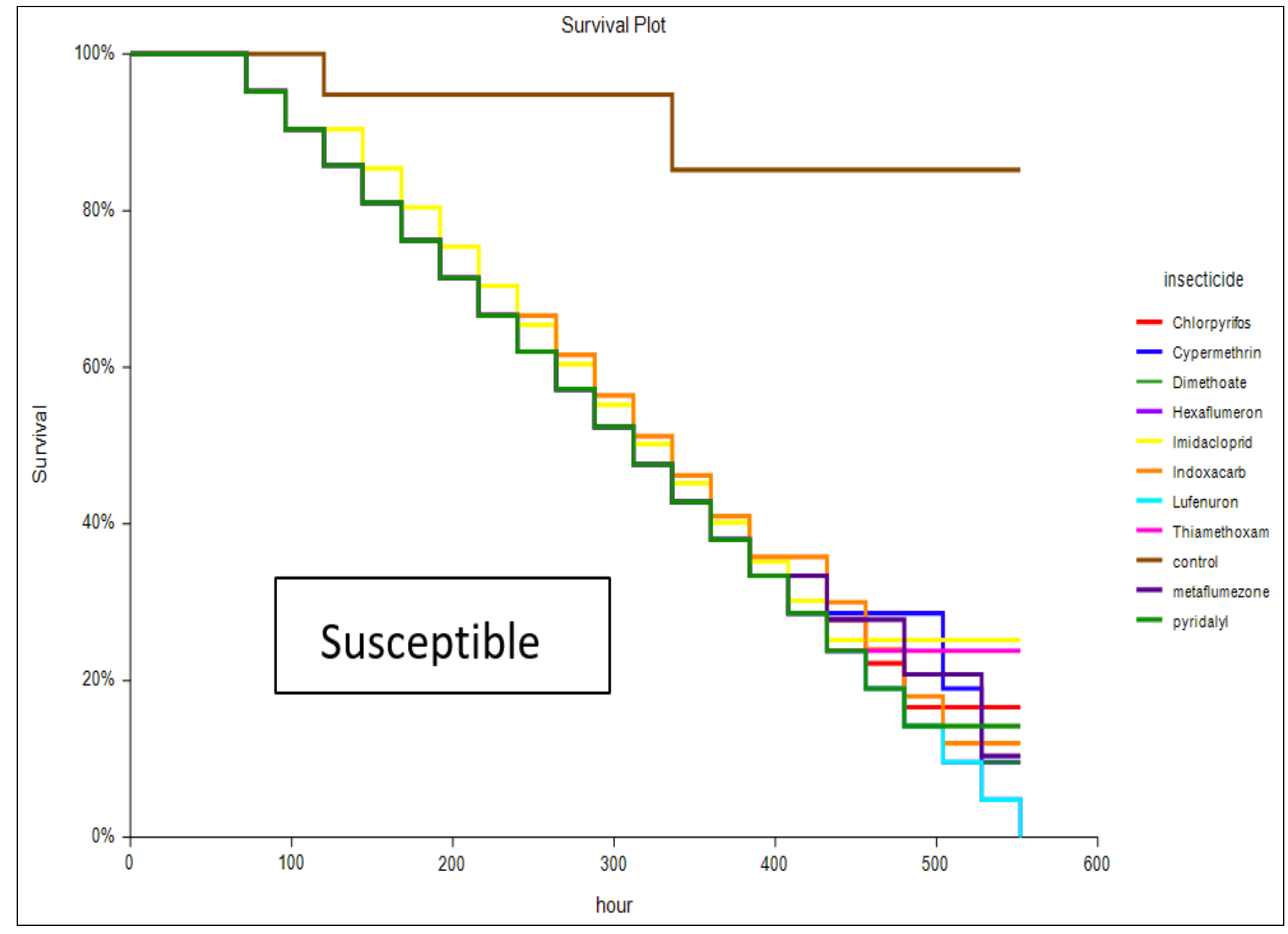




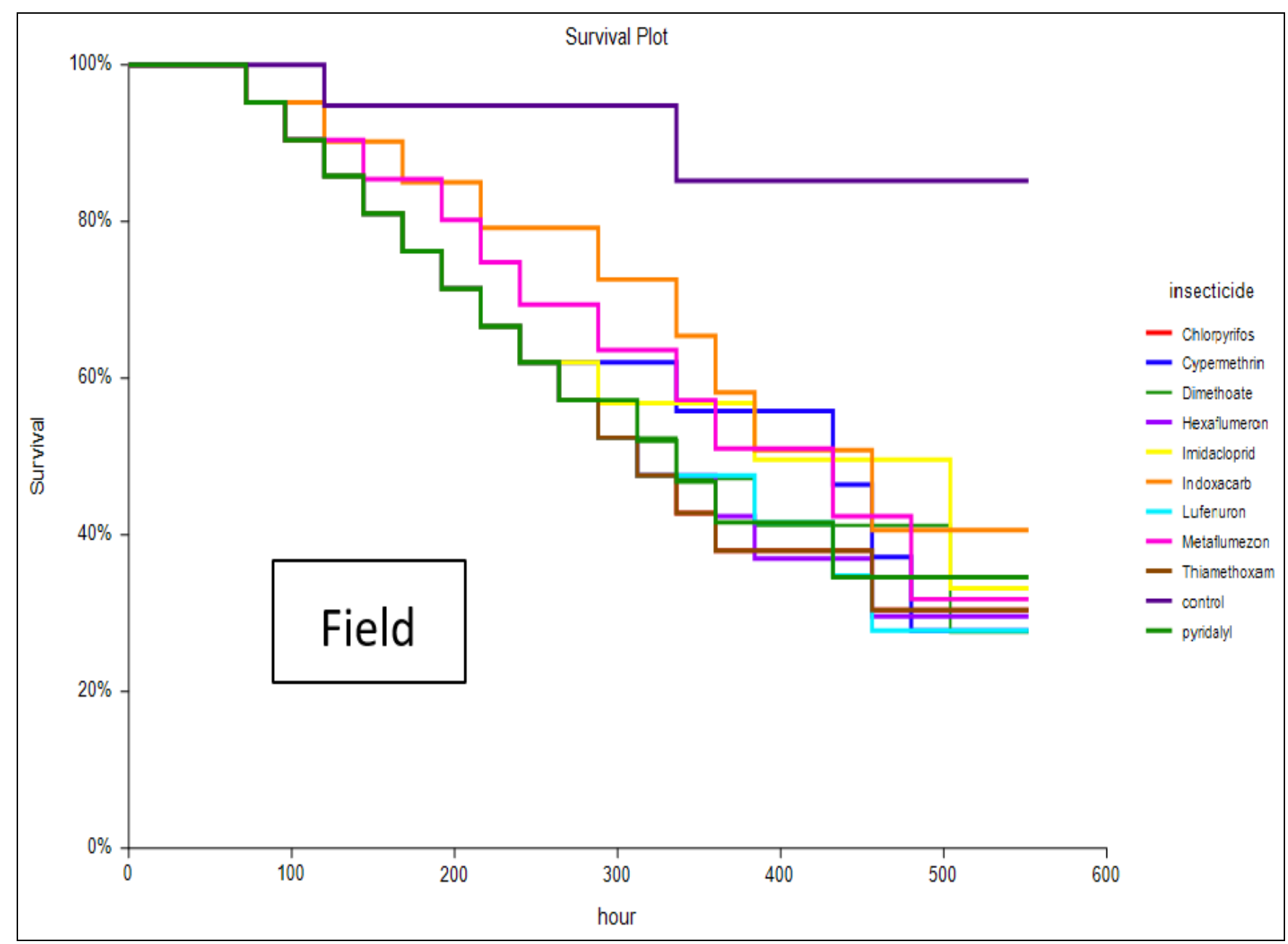

Fig 2: Susceptible and field survival curves from Kaplan Meier estimates determined the serial interval time to death alongside experiments duration from the day 1 of the $4^{\text {th }}$ instar larvae to moth emergence, oviposition and die. Censoring and the survival probability, number at risk, included for plotting curves, median survival time can be pointed out. Survival data are non-normal (skewed) so no distributional assumption. Survivorship curve result here of S.littoralis lifecycle, all are fall between one and two type, Pearl (1941) ${ }^{[25]}$.

Survival of any pest population normally depends on, exposure; pressure of multiple stressors like agro-chemicals, pathogens and poor food resources those causing population reductions. Bunya et al., $2016^{[5]}$, there was a decrease in survival at a parathion dose $20 \mathrm{mg} / \mathrm{kg}$, equall one-half of rat animals survived to 24 hours and to 8 days after poisoning, prove dose dependent calculated survival rate was $75,79 \%$ per day of sixth instars fall armyworm treated with azinophosmethyl and alphacypermethrin (Ali and Lutterell

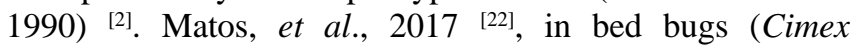
lectularius L.) fed on fipronil or clothianidin,, Nymph survivorship was depend on the presence of fed or unfed adults.

Table 6: Log-rank statistic and hazard rate for insecticide time-mortality assay of the S.littoralis susceptible and Field populations.

\begin{tabular}{|c|c|c|c|c|c|c|}
\hline & \multicolumn{3}{|c}{ Susceptible population } & \multicolumn{3}{c|}{ Field population } \\
\hline Insecticides & Z-Value & Standard Error & Standardized Z-Value & Z-Value & Standard Error & Standardized Z-Value \\
\hline Chlorpyrifos & 168.075 & 23.623 & 7.115 & 229.282 & 16.553 & 13.851 \\
\hline Cypermethrin & 160.985 & 22.913 & 7.026 & 117.08 & 19.087 & 6.134 \\
\hline Dimethoate & 255.322 & 23.906 & 10.680 & 203.096 & 16.339 & 12.43 \\
\hline Metaflumezone & 58.300 & 27.171 & 2.146 & 60.539 & 18.553 & 3.263 \\
\hline Hexaflumeron & 293.816 & 24.350 & 12.066 & 175.985 & 17.927 & 9.817 \\
\hline Imidacloprid & 34.060 & 25.548 & 1.333 & 171.032 & 15.564 & 10.989 \\
\hline Indoxacarb & 126.666 & 24.801 & 5.107 & -49.332 & 19.333 & -2.552 \\
\hline Lufenuron & 296.929 & 25.049 & 11.854 & 158.262 & 16.423 & 9.636 \\
\hline Thiamethoxam & 82.005 & 24.784 & 3.309 & 207.743 & 18.277 & 11.366 \\
\hline Pyridalyl & 277.670 & 20.173 & 13.764 & 156.576 & 16.413 & 9.54 \\
\hline Control & -1753.828 & 37.320 & -46.994 & -1430.265 & 31.948 & -44.768 \\
\hline
\end{tabular}

The logrank test is testing the equality of hazard functions or estimated survival times. The test imply for susceptible, Chi-Square $=$ 2257.250, DF $=10$, Probability Level $=0.0000$, Randomization Test Probability Level $=0.0050$ (200 Monte Carlo Samples) Weighting of Hazard Comparisons across Time $=$ Equal. For field, Chi-Square $=2414.278$, DF $=10$, Probability Level $=0.0000$ Randomization Test Probability Level = 0.0050 (200 Monte Carlo Samples) Weighting of Hazard Comparisons across Time $=$ Equal. 
For testing the survival curves, and if the hazard rates, of two or more populations are equal, at all times less than the maximum observed time, hypothesis testing were computed. The alternative hypothesis is that at least two of the hazard rates are different at some time less than the observed maximum time (Table 7). The null hypothesis means that there is no difference between the groups of insecticide treatment.

Table 7: One-Sample T-Test Report, Tests of Assumptions.

\begin{tabular}{|c|c|c|c|c|c|c|}
\hline \multirow{2}{*}{ Different Test of Assumption } & \multicolumn{3}{|c|}{ Susc. population } & \multicolumn{3}{c|}{ Field population } \\
\cline { 2 - 7 } & Value & Prob Level & Decision $(\boldsymbol{\alpha}=\mathbf{0 . 0 5 0})$ & Value & Prob Level & Decision (a) 0.050) \\
\hline Shapiro-Wilk Normality & 0.913 & 0 & Reject normality & 0.836 & 0 & Reject normality \\
\hline Skewness Normality & 4.591 & 0.000004 & Reject normality & 5.578 & 0 & Reject normality \\
\hline Kurtosis Normality & -0.363 & 0.716326 & Cannot reject normality & -0.813 & 0.415921 & Cannot reject normality \\
\hline Omnibus Normality & 21.213 & 0.000025 & Reject normality & 31.784 & 0 & Reject normality \\
\hline Martinez-Iglewicz & 1.039 & 0 & Reject normality & 0.955 & 0 & Can't reject normality \\
\hline Kolmogorov-Smirnov & 0.119 & 0 & Reject normality & 0.097 & 0 & Reject normality \\
\hline D'Agostino Skewness & -33.184 & 0 & Reject normality & -20.50 & 0 & Reject normality \\
\hline D'Agostino Kurtosis & -7.96 & 0 & Reject normality & -25.11 & 0 & Reject normality \\
\hline
\end{tabular}

Table (7), shows that p-values are less than 0.05 , this means that the null hypothesis is success to be rejected. Then the survival curves of within insecticide groups and within population and control were differ. Holbrook, et al., 2002 ${ }^{[8]}$, the detection of low levels of fipronile resistance in the
German cockroach using logistic regression and resistance ratios are relatively ineffective in distinguishing differences between strains, but dose-mortality or time-mortality data are improved method involves proportional hazards modeling, known as Cox regression.

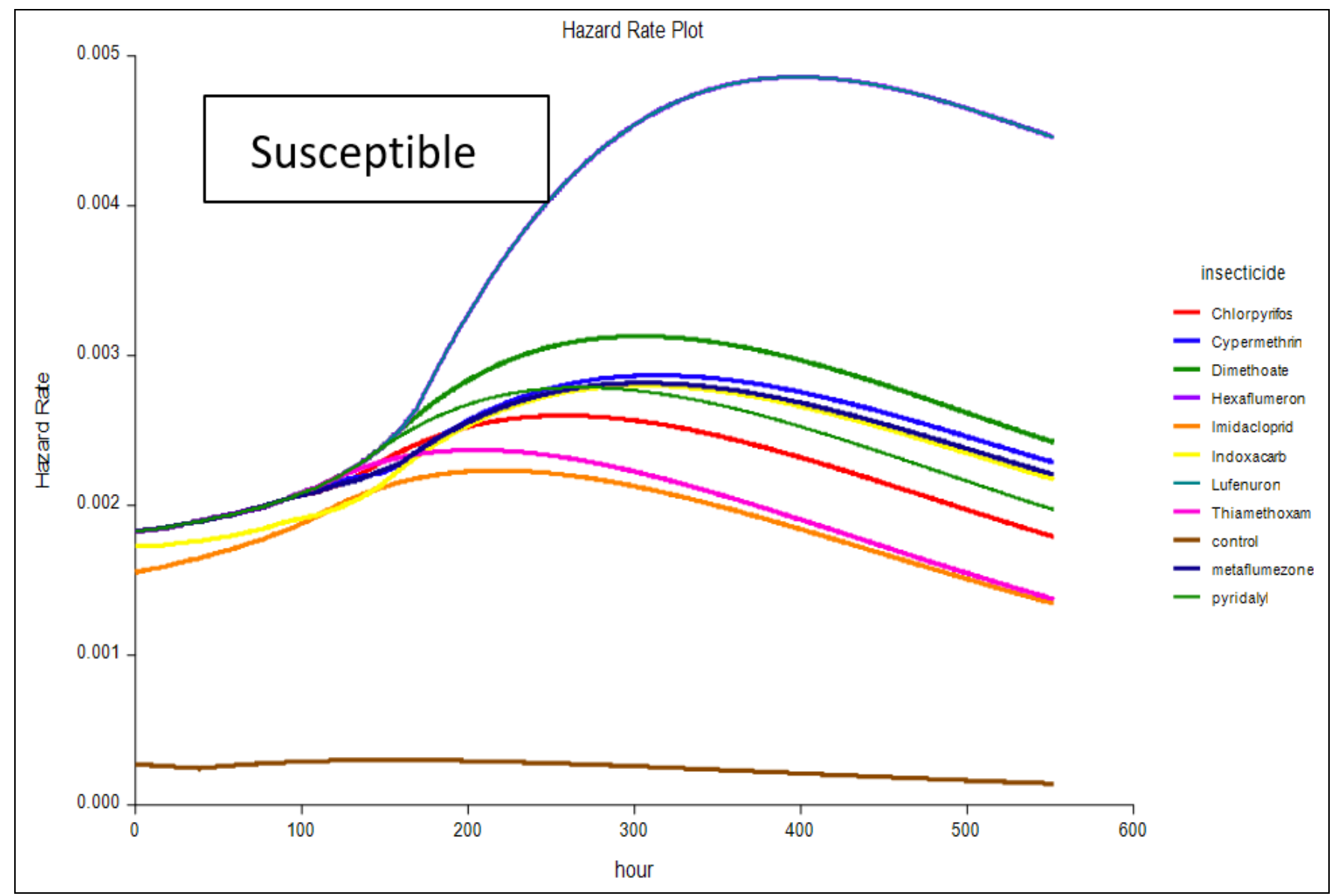




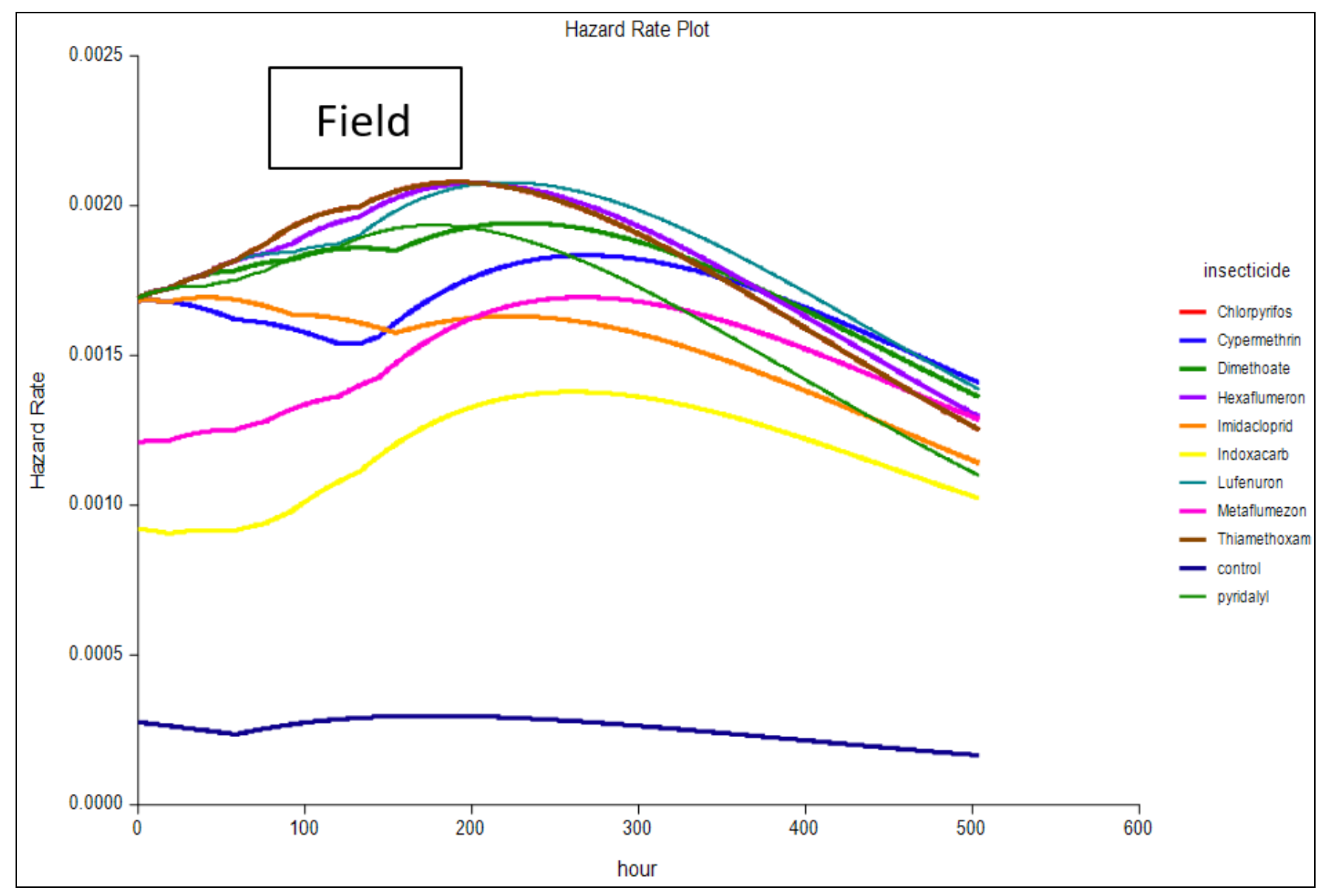

Fig 3: The probability distribution of individuals at time $\mathrm{T}$ of certain events itself could roll the event of the next prompt generating conditional failure rate in reliability this is the Hazard rate, $\mathrm{h}(\mathrm{T})$ : or the age specific failure rate, that has a different hazard rate function. It is essential in computing and quantifying events in survival analysis.

Table 8: Hazard ratio-Cox-Mantel Logrank Test in relation to control (Cox-Mantel Logrank Test).

\begin{tabular}{|c|c|c|c|c|c|c|c|c|c|c|}
\hline & \multicolumn{4}{|c|}{ Susc. population } & \multicolumn{5}{c|}{ Field population } \\
\hline Group Ratio & Hazard Ratio & Chi-Square & Prob Level & Lower & Upper & Hazard Ratio & Chi-Square & Prob Level & Lower & Upper \\
\hline control/Chlorpyrifos & 0.08 & 1627.194 & 0.0000 & 0.07 & 0.09 & 0.07 & 1786.251 & 0.0000 & 0.06 & 0.09 \\
\hline control/Cypermethrin & 0.08 & 1615.426 & 0.0000 & 0.07 & 0.09 & 0.09 & 1250.187 & 0.0000 & 0.08 & 0.11 \\
\hline control/Dimethoate & 0.07 & 1884.783 & 0.0000 & 0.06 & 0.08 & 0.07 & 1656.557 & 0.0000 & 0.06 & 0.09 \\
\hline control/Metaflumezone & 0.10 & 1406.291 & 0.0000 & 0.08 & 0.11 & 0.1 & 1092.277 & 0.0000 & 0.08 & 0.12 \\
\hline control/Hexaflumeron & 0.07 & 2023.117 & 0.0000 & 0.06 & 0.08 & 0.08 & 1505.797 & 0.0000 & 0.07 & 0.1 \\
\hline control/Imidacloprid & 0.10 & 1320.451 & 0.0000 & 0.09 & 0.11 & 0.08 & 1488.066 & 0.0000 & 0.06 & 0.1 \\
\hline control/Indoxacarb & 0.09 & 1539.402 & 0.0000 & 0.08 & 0.10 & 0.13 & 751.388 & 0.0000 & 0.11 & 0.16 \\
\hline control/Lufenuron & 0.07 & 2011.115 & 0.0000 & 0.06 & 0.08 & 0.08 & 1465.173 & 0.0000 & 0.07 & 0.1 \\
\hline control/Thiamethoxam & 0.09 & 1415.214 & 0.0000 & 0.08 & 0.11 & 0.08 & 1618.578 & 0.0000 & 0.07 & 0.09 \\
\hline control/pyridalyl & 0.07 & 2030.946 & 0.0000 & 0.06 & 0.08 & 0.08 & 1454.114 & 0.0000 & 0.07 & 0.1 \\
\hline
\end{tabular}

Hazard ratio is the relative survival between groups garnered from proportional hazards models and if less than one it refer to that individual males of a field population were dying more slowly than the susceptible population.

The results concluded about time mortality assay using Kaplan-Meier and Cox regression analysis methodology were accurate and provide clear decision about pesticide toxicity elucidation, pesticide efficiency status and differences. The hazard ratios of insecticides in relation to control and their $95 \%$ confidence intervals of the susceptible and field calculated were smaller than one (Table 7). This is a great indication that field population were dying at a significantly slower rate than susceptible. Males of the indoxacarb insecticide in field were found to be about onethird (hazard ratio: 0.13/0.09) as possible to die at any point in time more than males from the susceptible. Some theoretical demonstrations about survival argument after organism exposed to stress like insecticides ranged from low to high toxic effect, some of it as follows. The wood frog 15 populations exposed to carbaryl, and tolerance pattern noticed in consistency with theoretical predictions, that populations was closed to agriculture displayed constitutive tolerance to carbaryl whereas populations far from agriculture had low native tolerance but high magnitudes of induced tolerance (Hua, et al., 2015). 

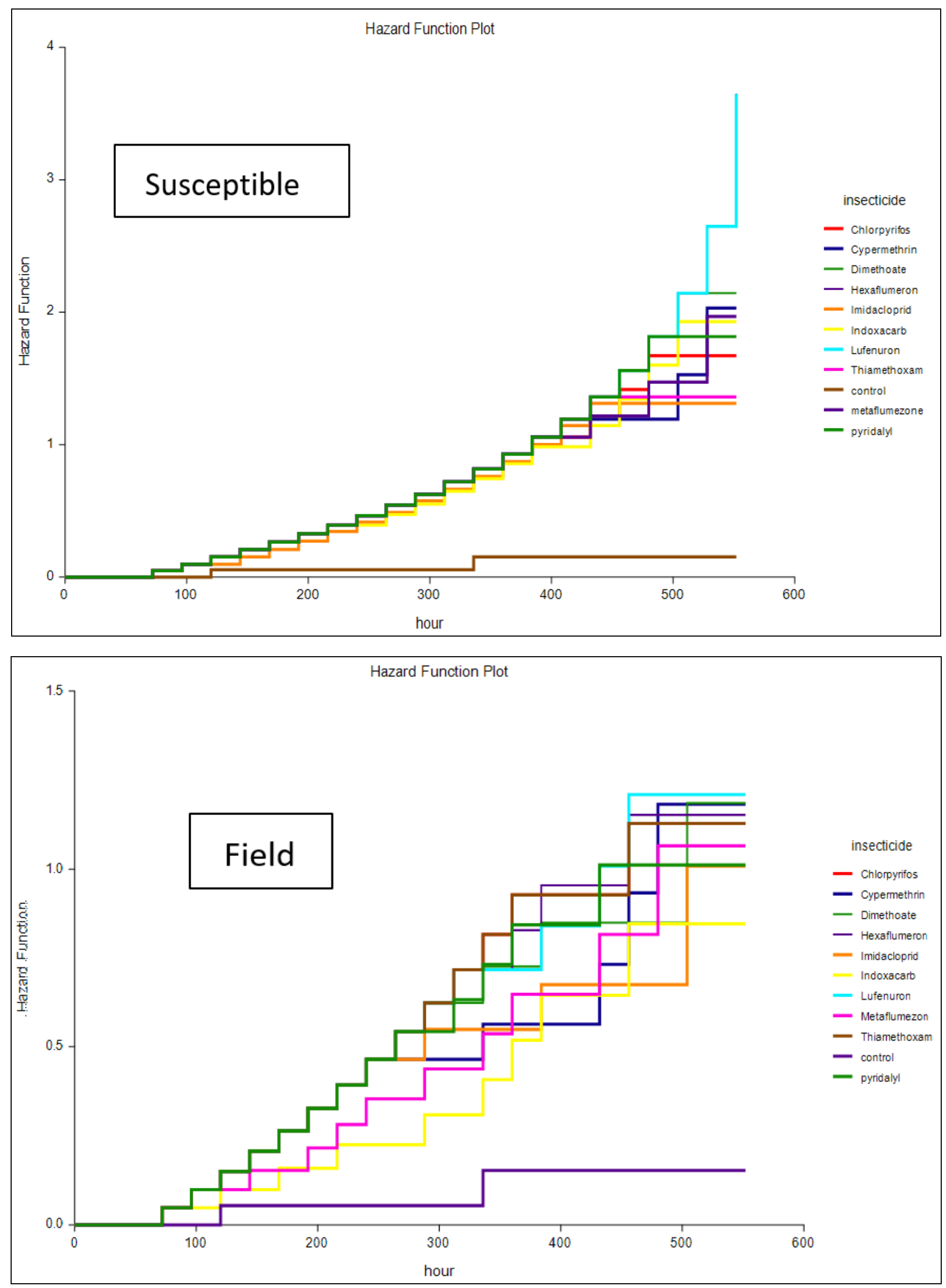

Fig 4: The hazard function or death rate is the prompt probability of deaths for individuals that still alive. 
Papachristos, et al., $2008^{[12]}$, study the of the Mediterranean fruit fly, Ceratitis capitata (Wiedemann) (Diptera: Tephritidae), immature stages on the lemon, and bitter oranges had strong effects on larval performance and survival, essence of the peel was the most critical, inducing very high mortality rates. Survival of larvae ranged from zero for all varieties tested to $22.5 \%$, except for bitter orange $(76 \%)$. Survival of pupae was high for all varieties tested (81.1-90.7\%). Kingsolver et al., $2011^{[17]}$, study the changes in temperature-dependence of Manduca sexta population growth can affect juvenile survival and adult reproduction. High temperatures prevent survival to maturity. The differing in responses of multiple life stages is essential to understand the ecological and evolutionary consequences of climate change. Lashkari, et al., $2007^{[19]}$, found no significant differences in aphid life-table parameters between the two imidacloprid and pymetrozine treatment on population growth parameters of cabbage aphid, Brevicoryne brassicae L. (Homoptera: Aphididae). Cox regression coeffecient, was computed to the timemortality data using logistic models for all insecticide fit model (ranged from 0.0061 to 0.46 for susceptible and -0.17 to 0.47 for field), of the susceptible and field strains. If the coefficient was negative means the insecticide was very effective on the pest, but the maximum value means the insecticide loss efficiency to control the pest. The regression coefficient were supported in itself, with significant Wald statistic consists of $\mathrm{Z}$ test, probability level, pseudo $\mathrm{R}^{2}$.

Table 9: Regression Coefficient (B) of Cox proportion hazard test model for S.littoralis susceptible and field population mortality analysis taking risk ratio, in relation to pyridalyl insecticide.

\begin{tabular}{|c|c|c|c|c|c|c|c|c|c|c|c|c|}
\hline & \multicolumn{6}{|c|}{ Susceptible Population } & \multicolumn{6}{|c|}{ Field Population } \\
\hline & Coefficient & Risk Ratio & & Wald & Prob & Pseudo & Coefficient & Risk Ratio & & Wald & Prob & Pseudo \\
\hline Insecticide & (B) \pm SE & $\operatorname{Exp}(B)$ & Mean & Z-Value & Level & $\mathbf{R}^{2}$ & (B) $\pm \mathrm{SE}$ & $\operatorname{Exp}(B)$ & Mean & Z-Value & Level & $\mathbf{R}^{2}$ \\
\hline Chlorpyrifos/ & $0.1408 \pm 0.039$ & 1.151 & 0.012 & 3.59 & 0.0003 & 0.0014 & $0.439 \pm 0.044$ & 1.55 & & 9.96 & 0 & 0.0188 \\
\hline Cypermethrin/ & $0.006 \pm 0.045$ & 1.006 & 0.007 & & 0.8934 & 0 & $0.257 \pm 0.042$ & 1.29 & 017 & 6.12 & 0 & \\
\hline Dimet & 319 & & 0.015 & & 0 & 0.0099 & $0.357 \pm 0.046$ & 1.42 & & & 0 & \\
\hline Meta & & & & & 0 & & & 0.83 & & & 0.0001 & \\
\hline Hexaf & 0.39 & 49 & 0.016 & 2.38 & 0 & 0.0169 & 459 & 1.46 & 0.009 & 8.29 & 0 & \\
\hline Imida & 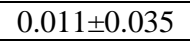 & & 0.020 & & 0.7407 & 0 & $0.191 \pm 0.052$ & 1.21 & -0.000 & 3.66 & 0.0002 & \\
\hline Indo & $.111 \pm 0.035$ & & 0.017 & 13 & 0.0017 & 0.0011 & $-0.546 \pm 0.05$ & 0.57 & 0.020 & -10.75 & 0 & 0.0219 \\
\hline Lufenuron/ & 0.030 & & 0.020 & & 0 & 0.0258 & $0.307 \pm 0.057$ & 1.36 & -0.000 & 5.38 & 0 & 056 \\
\hline Thiamethoxam/ & & & & & 0.0105 & 0.0007 & & 1.60 & & & 0 & \\
\hline Control & $-1.922 \pm 0.155$ & 0.14 & 0.107 & -12.36 & 0 & 0.0168 & $-1.96 \pm 0.173$ & 0.139 & 0.162 & -11.3 & 0 & 0.0242 \\
\hline
\end{tabular}

Cox-Mantel and Mantel-Haenszel Logrank Tests; the Low Rank refer to events happening later in time.

Many literature cited such results about insect exposed to stress as honeybee workers exposed to sub-lethal doses of diet containing thiacloprid show higher survival rates was 11 days post exposure than controls Dickel et al., (2018) ${ }^{[10]}$. Coulon et al., (2018) ${ }^{[8]}$, found statistical differences between survival curves according to Kaplan-Meier estimation between control bees and bees exposed to 2.5 $\mathrm{ng} / \mathrm{bee} /$ day of thiamethoxam. Also combined neonicotinoid pesticide and parasite stress to honeybee queens' alter physiology and survival (Dussaubat et al., 2016) ${ }^{[11]}$. All literature agree with the interpretation of the variation in survival observation within a population return to the biochemical process responsible for insecticide insect body eliminations or detoxifications.

\section{Refferences}

1. Aalen OO, Johansen S. An Empirical Transition Matrix for Non-Homogeneous Markov Chains Based on Censored Observations. Scandinavian Journal of Statistics 1978;5:141-150.

2. Ali A, Lutterell RG. Survival of fall armyworm (Lepidoptera: noctuidae) immatures on cotton. Florida entomologist 1990;73(3):459-465.

3. Brevik K, Schoville SD, Mota-Sanchez D, Chen YH. Pesticide durability and the evolution of resistance: A novel application of survival analysis. Pest Manag Sci 2018;74:1953-1963.

4. Brookmeyer R, Crowley J. A confidence interval for the median survival time. Biometrics 1982;38:29-41.

5. Bunya N, Sawamoto K, Benoit H, Bird SB. The Effect of Parathion on Red Blood Cell Acetylcholinesterase in the Wistar Rat. Journal of Toxicology, 2016, Article ID
4576952, 5 pages.

6. Clark TG, Bradburn MJ, Love SB, Altman DG. Survival Analysis PartI: Basic concepts and first analyses. British Journal of Cancer 2003;89:232-238.

7. Cox DR. Regression models and life tables. Journal of the Royal Statistical Society 1972;B34:187-220.

8. Coulon MF, Schurr Martel AC, Cougoule N, Bégaud A, Mangoni P, Dalmon A et al. Survival analysis for the detection of low-level insecticide resistance. Proceeding of the 4th international conference on urban pests 2002, $159-166$.

9. De Castro AA, Corrêa AS, Legaspi JC, Guedes RNC, Serrão JE, Zanuncio JC. Survival and behavior of the insecticide-exposed predators Podisus nigrispinus and Supputius cincticeps (Heteroptera: Pentatomidae). Chemosphere 2013;93:1043-1050.

10. Dickel F, MuÈnch D, Amdam GV, Mappes J, Freita D. Increased survival of honeybees in the laboratory after simultaneous exposure to low doses of pesticides and bacteria. PLoS ONE 2018;13(1):e0191256.

11. Dussaubat C, Maisonnasse A, Crauser D, Tchamitchian $\mathrm{S}$, Bonnet $\mathrm{M}$, Cousin $\mathrm{M}$ et al. Combined neonicotinoid pesticide and parasite stress alter honeybee queens' physiology and survival. Sci. Rep 2016;6:31430.

12. Dimitrios P, Papachristos Nikos T, Papadopoulos George Nanos D. Survival and Development of Immature Stages of the Mediterranean Fruit Fly (Diptera: Tephritidae) in Citrus Fruit. J. Econ. Entomol 2008;101(3):866-872.

13. Etikan İ, Abubakar S, Alkassim R. The Kaplan Meier Estimate in Survival Analysis. Biom Biostat Int $\mathbf{J}$ 2017;5(2):00128. 
14. Finney DJ. Probit Analysis. Cambridge University Press 1971.

15. Goel MK, Khanna P, Kishore J. Understanding survival analysis: Kaplan-Meier estimate. Int $\mathbf{J}$ Ayurveda Res 2010;1(4):274-278.

16. Hua J, Jones DK, Mattes BM, Cothran RD, Relyea RA, Hoverman JT. The contribution of phenotypic plasticity to the evolution of insecticide tolerance in amphibian populations. Evolutionary Applications published by John Wiley \& Sons Ltd 2015;8:586-596.

17. Joel G, Kingsolver H, Woods A, Buckley LB, Potter KA, MacLean HJ et al. Complex Life Cycles and the Responses of Insects to Climate Change. Integrative and Comparative Biology 2011;51(5):719-732.

18. Kaplan EL, Meier P. Nonparametric estimation from incomplete observations. Journal of the American Statistical Association 1958;53:457-81.

19. Lashkari MR, Sahragard A, Ghadamyari M. Sublethal effects of imidacloprid and pymetrozine on population growth parameters of cabbage aphid, Brevicoryne brassicae on rapeseed, Brassica napus L. The Authors Insect Science 2007;14:207-212.

20. Lee ET, John Wang W. Statistical Methods for Survival Data Analysis, Third Edition. Book Series: Wiley Series in Probability and Statistics 2003.

21. Mantel N, Haenszel W. Statistical aspects of the analysis of data from retrospective studies. Journal of the National Cancer Institute 1959;22:719-748.

22. Matos YK, Sierras A, Schal C. Evaluation of the Potential for Secondary Kill for Ingested Insecticides in the Common Bed Bug (Hemiptera: Cimicidae). Journal of Economic Entomology 2017;110(3):1218-1225.

23. NCSS-2019, Statistical Software. NCSS, LLC. Kaysville, Utah, USA 2019. ncss.com/ software/ncss.

24. Nelson W. A Short Life Test for Comparing a Sample with Previous Accelerated Test Results. Technometrics 1972; 14:175-185.

25. Pearl A, Park T, Miner JR. 'Experimental studies on the duration of life. XVI. Life tables for the flour beet 1941.

26. Paramasivam M, Selvi C. Laboratory bioassay methods to assess the insecticide toxicity against insect pests-A review. Journal of Entomology and Zoology Studies 2017;5(3):1441-1445.

27. Shaaban AM, Abo-Elghar MR, Abdel-Mohymen MR, El-Malla MA. Resistance of the Egyptian cotton leafworm, Spodoptera littoralis (Boisd.), to certain insecticides. Zeitschrift für Pflanzenkrankheiten und Pflanzenschutz / Journal of Plant Diseases and Protection 1985;92(1):69-75.

28. Sternberg ED, Thomas MB. Insights from agriculture for the management of insecticide resistance in disease vectors. Evolutionary Applications 2018;11:404-414.

29. Throne JE, Weaver DK, Chew V, James Baker E. Probit analysis of correlated data: multiple observations over time at one concentrate ion. Journal of Economic Entomology 1995;88(5):1510-1512. 